\title{
OSWALDO TREJO: \\ PAUTAS PARA UNA PROPUESTA \\ DE LA (IN)COMUNICACIÓN LITERARIA
}

POR

LUIS BARRERA LINARES

Tanto se ha hablado en Venezuela de ciertas rupturas con el "realismo" y con el "criollismo" que uno a veces se pregunta si en verdad esto ha sido un hecho que marcó la narrativa nacional posterior a los años treinta o cuarenta, o si, por el contrario, esa "ruptura" ha sido más una reformulación, un cambio de perspectiva en la interpretación literaria del paisaje, del localismo, de lo regional. El escenario urbano cambiaba y con él cambiaban también los modos de captarlo para la literatura. Variaba además la manera de convertirlo en un texto literario que aspirara a trascender mucho más allá del mero retrato, de la repetición fotográfica o de la descripción objetiva, si ello de verdad fuera posible.

Para finales de los cuarenta, nuevos tiempos vendrían para el quehacer literario nacional, sobre todo a partir de la obra de cultivadores de la narrativa breve que luego se consagrarían como grandes cuentistas. Entre ellos podemos mencionar a Gustavo Díaz Solís (Marejada, 1940; Llueve sobre el mar, 1943; Cuentos de dos tiempos, 1950), Andrés Mariño Palacio (El limite del hastio, 1946; Los alegres desahuciados, 1948), Antonio Márquez Salas (El hombre y su verde caballo, 1947), Alfredo Armas Alfonzo (Los cielos de la muerte, 1940), Óscar Guaramato (Biografia de un escarabajo, 1949), Pedro Berroeta (Marianik, 1945), Humberto Rivas Mijares (El murado, 1949) y OswaldoTrejo (Los cuatro pies, 1948; Escuchando al idiota, 1949), autor este último cuya trayectoria literaria se inicia en esa década y se extiende hasta el presente.

Puede apreciarse en este grupo de cuentistas cierta preocupación común (y tácita, quizás) por la búsqueda constante de nuevas formas para la narración breve. En casi todos parece habitar un interés por la delimitación psicológica de sus personajes. Sin descuidar totalmente la relevancia del marco externo de la narración se muestran reacios a veces al exteriorismo paisajista o se sitúan como observadores del espacio geográfico en función de sus implicaciones para la conciencia de los personajes. Es ésta la misma época del llamado grupo venezolano Contrapunto, al cual estuvieron vinculados algunos de los autores referidos. Diez años de gestación incesante y de preocupaciones estéticas bastante reflexivas que luego darían su fruto en los años subsiguientes con la definitiva consagración de la obra de Díaz Solís, Márquez Salas, Armas Alfonzo, Guaramato y Trejo, aunque el verdadero aporte de los dos últimos no haya sido suficientemente reconocido hasta el presente. En Guaramato coincidían por ejemplo, dos rasgos determinantes y definitivos para la factura del cuento: la economía de la palabra y la certeza de un estilo verbal que, siendo casi 
siempre metafórico, apuntaba hacia la claridad de la anécdota. Aquí radica la razón para que algunos investigadores - Javier Lasarte (1991), por ejemplo- lo vinculen a ese otro gran cuentista que es Gustavo Díaz Solís. Aparte de un innegable acercamiento al tono lírico, confluyen en ambos varios factores que más adelante serían definitivos para la consolidación del cuento venezolano y que curiosamente alcanzarían su mayor esplendor en textos de Guillermo Meneses, a quien puede considerarse el gran narrador venezolano de los últimos cincuenta años.

Por otra parte, y desde una perspectiva distinta en lo referente al predominio de la forma sobre los contenidos del texto narrativo será Oswaldo Trejo (Ejido, Estado Mérida, Venezuela, 1924) quien decrete un poco más adelante la irrelevancia de la anécdota para la constitución del relato. El lenguaje será para éste casi lo único valedero a la hora de estructurar la narración, cuestión que ya se asomaba en su primer libro de cuentos, Los cuatro pies (1948) y que sería confirmada por buena parte de su obra posterior (Cuentos de Ia primera esquina, 1952; Depósito de seres, cuentos, 1963; Andén lejano, novela, 1968; Textos de un texto con Teresas, novela, 1975; Al trajo trejo, troja, trujo, treja, traje, trejo, cuentos, 1980; Una sola rosa y una mandarina, cuentos, 1985; Metástasis del verbo, novela, 1990). ${ }^{1}$

Se trata de un narrador aceptado generalmente como integrante de nuestra oficialidad literaria, posición refrendada por el otorgamiento del Premiơ Nacional de Literatura (1988). Es un escritor a quien la crítica destaca usualmente como "curioso", "extraño", achacándole el apelativo de "prosista experimental", llegándose a poner en duda incluso la estructura "narrativa" de sus textos y expresándose serias observaciones acerca del nivel de comunicabilidad de los mismos. Con sus publicaciones últimas pasará a constituirse en una especie de antimodelo comunicativo en cuanto que desde varios puntos de vista violenta buena parte de lo que literatura significa como "acto comunicativo ritual" (van Dijk 1980).

Precisamente, una de sus particularidades dentro del diasistema de la literatura venezolana contemporánea radica en que la mayoría de los investigadores que se han ocupado de su obra se refieren reiteradamente a las dificultades de acceso que la misma ofrece al lector. "Un universo como el de Trejo —dice Oropeza $(1984,338)$ - se apoya fundamentalmente en el lenguaje, en la palabra que, continuamente, se hace, se construye". En casi toda su obra no parecieran tener cabida ni las formas de escritura tradicional ni la sintaxis narrativa habitual (Tedesco 1981). Cada vez que se alude a su literatura se hace referencia a lo problemático de su captación, a las dificultades o aprietos en que coloca al lector que desee acercarse a la misma. De acuerdo con ello, un buen número de sus narraciones suele plantear implícita o explícitamente el problema mismo de la imposibilidad de la comunicación y es simultáneamente generador de incomunicación con el lector convencional. Esto es, parecieran estar dirigidos hacia un destinatario ideal cuyas dimensiones exigen un alto convencimiento acerca de las virtudes del arte por el arte, una concepción literaria en la que se acepte la necesaria inmersión y co-participación del receptor en la elaboración misma del discurso literario al que se enfrenta. Un receptor dispuesto a entrar en el carácter lúdico de ciertos textos en la ironía con que parecen

\footnotetext{
${ }^{1}$ Dada la necesidad de recurrir con mucha frecuencia a la cita de los títulos de las obras del autor, en algunos casos nos permitiremos abreviarlas mencionando las primeras dos o tres palabras del título. P.e.: Una sola rosa ..., Al trajo trejo ..., También los hombres ..., etc.
} 
plantear el fenómeno de la (in)comunicación literaria a través de la burla, e incluso en el juego de proponer su propia aniquilación en medio de la crisis comunicacional contemporánea en la cual la literatura parece haber perdido su sentido estético y su carácter interactivo. Se habla asimismo de una narrativa que se va construyendo en la medida en que va siendo leída (Oropeza 1984).

Criticado, objetado, acusado a veces de extemporáneo, de hermético, de incomprensible, muchas veces soslayado por algunos de sus contemporáneos, Oswaldo Trejo ha sido al mismo tiempo merecedor de un reconocimiento que no deja de parecernos contradictorio: muchos aceptan el diseño desestabilizador de su literatura siempre que se hable de narrativa a la que más bien se considera antinarrativa, pero pocos se atreven a negar el valor estético de la misma. Su clara y consecuente orientación hacia lo que se denomina "el arte por el arte" lo coloca en una posición de autor paradigmático, aunque en verdad no son muchos los narradores venezolanos que hayan expresado la voluntad de establecer diálogo explícito y franco con sus concepciones de lo narrativo.

En el caso de Venezuela, Trejo vendría a constituir algo así como el prototipo de escritor más cercano a la concepción que hace del mismo un genuino representante de "lo culto" y elitesco: la literatura entendida como arte puro, no contaminante, ajena a la provocación de riesgos para un sistema que la alienta y la promueve como producto que contribuye a su reafirmación. Es decir, lo literario definido como recurso cultural ajeno a la masificación. Motivo suficiente para que las disquisiciones teóricas relacionadas con las potencialidades comunicativas del arte sean ajenas al creador mismo. No es en realidad que no interese el fenómeno de la comunicación mediante los textos literarios, sino que esto no constituye un problema particular para el escritor por cuanto supone dirigirse a una élite que comparte sus mismos criterios al respecto: el texto se genera entonces bajo los auspicios de un supuesto código cuya concreción será más efectiva en la medida en que los potenciales receptores (que nunca serán demasiados), sus lectores ideales, conformen una pequeña congregación de iniciados en esas lides. Pero cuidado: tampoco creemos que ello signifique pecado estético alguno. Se trata sencillamente de una conceptualización particular (una más) acerca del valor social del arte. Reprobar o no sus propósitos no es objetivo nuestro en este caso. Entender lo que la misma pueda implicar en sus relaciones con lo literario como fenómeno comunicativo es lo que más nos interesa.

Otro detalle interesante relacionado con el nivel de legibilidad de su obra radica en acercar constantemente sus "textos" - pocos se atreven a denominarlos abiertamente "cuentos", "relatos" o "narraciones"- a la poesía. ${ }^{2}$ Lo que posiblemente deba entenderse como que el supuesto bajo nivel de comprensión de los mismos radica en que probablemente se está leyendo como narrativa algo que en verdad anda mucho más cerca del discurso lírico. Es obvio que hay en esta propuesta una cierta confusión entre la categorización genérico-literaria de un determinado discurso y los rasgos textuales que contiene. $O$ una contraposición forzada entre lo que debe ser considerado como narrativo y como lírico,

\footnotetext{
${ }^{2}$ Al hablar de la noción de "legibilidad" desde el punto de vista comunicacional, nos referimos específicamente al concepto que de la misma maneja, entre otros, Dubois (1983): en tal sentido, el grado de legibilidad de un texto literario se relaciona con el nivel de aptitud que el mismo posee para permitir su decodificación por parte del lector.
} 
cuestión que no tiene por qué ser así. La clasificación genérica puede estar relacionada con el predominio de ciertas marcas textuales particulares, pero de allí a suponer que lo narrativo no puede ser lírico hay notables diferencias. Tampoco creemos que tal grado de ilegibilidad sea el mismo en toda la cuentística del autor. Apreciamos más bien un proceso de oscilaciones comunicativas que pareciera haberse desplazado desde un cierto nivel intermedio - localizado, por ejemplo, en Los cuatro pies, 1948 - atenuado favorablemente para el lector en otros libros (Cuentos de la primera esquina, 1952; Depósito de seres, 1963) y llevado a extremos peligrosos por el incremento de su nivel de inaccesibilidad en volúmenes como $\mathrm{Al}$ trajo trejo ... (1980) y —quizás menos— en Una sola rosa ... (1985). Precisamente queremos detenernos en estos dos últimos por considerarlos como los libros de cuentos más representativos a la hora de hablar de una propuesta anticomunicacional de la literatura. Abordaremos ambos volúmenes a partir del contexto estético general en que han sido puestos en circulación. Veamos.

Si como tanto se ha dicho la convulsa década del sesenta resultó contradictoria para la literatura venezolana en general y mucho más para la narrativa, los años setenta se caracterizaron por una búsqueda quizás más definida hacia el llamado experimentalismo, pero también menos favorecedora para estimular los procesos de recepción del texto literario. Un acucioso y contundente trabajo publicado recientemente por Verónica Jaffé (1991) confirma este argumento al referirse a los procesos de recepción del nuevo cuento venezolano durante ese lapso. El análisis de esta autora ofrece importantes reflexiones acerca de una narrativa breve casi ajena a la consideración según la cual en todo hecho literario subyace una intención del emisor: apuntar hacia la activación de un acto verbal cuyo destino es la participación voluntaria de un receptor concreto que ofrece su propia posibilidad de confrontar lo que un determinado autor le ha ofrecido como objeto de creación literaria. Este hecho pareció no preocupar demasiado a buena parte de los cuentistas que publicaran libros durante la década estudiada por Jaffé en su libro. Uno de esos autores es precisamente Oswaldo Trejo, sobre quien la investigadora expresa lo siguiente:

... niega toda narratividad, introduciendo el texto en el espacio sugestivo de la poesía, insinuada ésta, además, por el ritmo interno de la prosa. La neutralidad, sugestión y ritmo del discurso son, en un sentido genérico, peculiaridades relacionadas con la poesía, con la cual se vincula también la importancia dada aquí a sensaciones, sentimientos, en detrimento de los hechos, personajes y sucesos. Los vacíos dejados por el texto se determinan escasamente con la constelación de personajes presentados (Jaffé 83).

El juicio de la autora se refiere casi exclusivamente a la secuela dejada por los cuentos recogidos en Al trajo trejo ... $\mathrm{y}$, en parte, a su novela Metástasis del verbo. Se le presenta entonces como un autor de textos breves en prosa que parece jugar definitivamente a la incomunicación. Un cambio notorio si aludimos a ciertos vaivenes que caracterizaron sus dos libros anteriores (Cuentos de la primera esquina, 1952 y Depósito de seres, 1952) ¿Qué ha ocurrido? ¿Una vuelta quizás a lą estética comunicacional subyacente de algunos de los cuentos recogidos en su primer libro publicado, Los cuatro pies? ¿Por qué ahora? ¿Por qué precisamente durante los años sesenta y no antes?

Intentaremos una explicación posible para este hecho refiriéndonos básicamente a la conformación de un nuevo contexto estético-cultural que de alguna manera favorecía la 
posibilidad de desarrollar la postura del arte por el arte. Luego nos detendremos en el análisis concreto de los dos últimos libros de cuentos del autor: Al trajo trejo ... (1980) y Una sola rosa ... (1985).

Lo que en otro trabajo hemos denominado la tendencia netamente narrativa de la cuentística venezolana - el cultivo abierto del llamado cuento anecdótico- se opacó bastante básicamente a partir del segundo lustro de los años setenta (véase Barrera 1992). En primer lugar, el país vive en esos momentos la consolidación de un "plan pacificador" puesto en práctica por los gobiernos de turno con la finalidad de aplacar las posturas y actitudes violentas asumidas desde los inicios de la democracia representativa (luego del derrocamiento de la dictadura de Marcos Pérez Jiménez, en 1958). Segundo, la repentina irrupción de un ambiente de bonanza económica, producto del alza de los precios del petróleo, contribuye a colocar la actividad artística dentro de un espacio social que puede considerarse como paradójica: un tanto marginal por su alejamiento del contexto político, pero oficialmente muy importante. El efluvio de la riqueza abundante crea el ambiente propicio para una relativa situación de paz social en la cual los escritores pasan a ser casi objetos decorativos, ajenos a la disidencia y ganados para el arte sin compromiso social, aunque investidos de cierta aureola mítica para el sistema que los aúpa. Por supuesto que esta generalización no incluye de ninguna manera a todo el contingente de escritores venezolanos de ese momento, pero si es indudable que llega incluso a aflojar las fuerzas de lucha de muchos de ellos, incluyendo a buena parte de los disidentes enguerrillados durante la década anterior. Será éste un tema digno de estudio de la historia contemporánea venezolana y no deseamos abundar en él sino para lo que creemos roza nuestro interés primordial en este trabajo: la comunicación a través del texto literario.

Casi ha desaparecido para ese momento toda aquella atmósfera sesentista dentro de la cual la palabra escrita con fines artísticos constituía un importante vehículo de comunicación que, sin sacrificar sus valores estéticos podía ser utilizada también como medio de combate que referenciara de manera crítica la situación socio-política existente. En teoría la urgencia del "compromiso" social del escritor implicó durante los sesenta la necesidad de buscar una comunicación casi inmediata con el lector, situación que se tornará muy distinta durante los años posteriores puesto que el interés proselitista de la literatura sería desplazado a un segundo lugar: el escritor pasará a centrarse entonces en el texto más que en el lector, sin que ello signifique que los anteriores no tuvieran ninguna preocupación por la forma del discurso, por el lenguaje. En verdad, ese interés nunca desapareció y si se quiere ser justo habría que hablar más bien de la búsqueda de un cierto equilibrio entre lo expresado por el escritor (el fondo) y la manera de hacerlo (la forma): ejemplos habría muchos pero permítasenos citar, entre otros, los nombres de Adriano González, León Luis Britto García, Gustavo Luis Carrera, Salvador Garmendia, Laura Antillano, Eduardo Liendo y Carlos Noguera, como probables paradigmas en este último sentido. En otros predios, Oswaldo Trejo y José Balza (en su primera etapa), por el contrario, andarían en una búsqueda mucho más elitista.

Ante el escaso impacto de un contexta histórico inmediato adormecido en la "buena vida", el fantasma del arte que se distancia del entorno y se fija más en sí mismo no se hace esperar. Caldo de cultivo propicio para que la literatura regrese a las posibilidades de exploración de la propia materia que le sirve de soporte: la palabra. El experimento, la 
exploración de los recursos verbales, los juegos tipográficos, la escritura automática, la reflexión existencialista, se implantan como elementos muy importantes para el diseño del discurso que se pretende literario. En el caso específico del cuento, hay (supuestamente) pocas historias relevantes que narrar y se pasa al extremo de literaturizar temas que pueden ser vistos como banales para el común de los lectores, o se llega inclusive a dar muy poca importancia a la referencia directa y abierta del hecho relatado. Narrar explícitamente una historia dentro de un cuento o una novela se convierte más bien una especie de pecado capital atribuible a todo aquel que desee ser considerado socialmente como escritor. Lo que alguna vez fue literario casi pasa al extremo marginal de lo antiliterario. El emisor del mensaje narrativo retoma viejos principios que afianzan su lugar dentro del proceso de producción del texto y la literatura deviene otra vez en una especie de acto narcisista para la autocontemplación: texto y autor se funden en un solo objetivo que distancia cada vez más la importancia de aquel destinatario que no sea el propio emisor o sus congéneres más cercanos. Desde esa ubicación que expande para la literatura su jerarquía de arte elitesco, ya no importa demasiado proponer al receptor concreto una "toma de conciencia" que lo inmiscuya en el compromiso asumido por el escritor con la sociedad para la cual escribe. Ahora el compromiso del escritor es consigo mismo y con el lenguaje que utiliza en la confección de sus propuestas, que obviamente colocan en un lugar muy privilegiado los viejos valores de la estética por la estética, ahora revitalizados.

En contraste con el entorno de los años precedentes y por lo menos en la apariencía, el país deviene durante los setenta en una especie de paraiso donde no existe problema que no tenga su solución a través de un intermediario tan fluido como el dinero, sin que a ello escapen los aspectos relacionados con el desarrollo de las artes. En el más mínimo detalle de la vida nacional, Venezuela enloquece ante la avalancha de dólares hasta el punto de que llega a hacerse merecedor del apelativo de "país saudita", sintagma que evoca los mundos paradisíacos en que supuestamente se sumergen algunas naciones árabes cuyo sustento es también el petróleo. ${ }^{3}$ Contexto indudablemente propicio para que la narrativa combatiente de otros momentos pierda su asidero referencial más importante y vuelva otra vez a volcarse sobre sí misma. En contraste con el interés más colectivo de otros momentos el arte parece abrir de nuevo las compuertas del individualismo. Cambia poco a poco la noción social del escritor, quien a su vez busca ahora sumergirse en su propia intimidad, en lugar de continuar con la mirada en un ambiente exterior que según él le ofrece muy pocas posibilidades literaturizables.

En el caso concreto de nuestra narrativa los modelos a seguir por los jóvenes escritores hablan por sí solos. Se afianza la fuerza generada por los textos más complejos (y más innovadores formalmente) de Guillermo Meneses. "La mano junto al muro" (cuento, 1951) y El falso cuaderno de Narciso Espejo (novela, 1952) son colocados en un lugar sacramental. Julio Garmendia continúa ascendiendo con relatos como "La tienda de muñecos" (1927) y - muy especialmente- "El cuento ficticio" (1957), desde su

\footnotetext{
${ }^{3}$ Para un análisis sobre las relaciones entre este fenómeno y el desarrollo específico de la narrativa, remito al trabajo de Beatriz González S. (1989). En cuanto a la posición social del escritor y su participación en el desarrollo de la vida política del país, hay algunas ideas explicativas en Santaella (1992): "Los escritores tienen la palabra" (El Nacional, 2-11-92, C/18).
} 
revitalización iniciada después de 1958. Oswaldo Trejo y Antonia Palacios encuentran eco para sus "texturas" entre los noveles narradores que asisten a los talleres literarios a intentar entender entre ellos mismos lo que buena parte de la gente común dice no captar. José Balza se enrumba como el pivote principal de una generación que lo menciona permanentemente como el sucesor más acertado de Meneses. Y en lo más alto, en la cumbre de la exacerbación descansa la figura ya más que idolatrada del poeta José Antonio Ramos Sucre.

Bajo el nombre de un narrador bastante convencional desde otra perspectiva (y muy criticado entre las nuevas generaciones), el Centro de Estudios Latinoamericamos "Rómulo Gallegos" abre sus puertas justo a mediados de la década (1975), y en su seno comienza a pulular lo más representativo de la nueva escritura. La Sección de Talleres Literarios precisamente dirigida durante varios años por Oswaldo Trejo- agrupa y aglutina así a buena parte de los cultores de una estética que se había mostrado a todas luces como elitesca y que además aceptaba sin remilgos que el Estado financiara no sólo su asistencia a los talleres - que en esos años era remunerada - sino también la edición de los libros generados como producto de esa actividad. $\mathrm{Y}$ así fue. $\mathrm{Y}$ allí están los textos, cuya colección se denominó "Voces Nuevas". Aunque a decir verdad no sobrevivieron para la literatura muchos de los participantes sino un reducido grupo de ellos. ${ }^{4}$

Los aspectos formales ganan así un considerable terreno y florece a diestra y siniestra la búsqueda de nuevas técnicas escriturales y de procesos de elaboración textual que recuerdan de alguna manera los procedimientos propios de ciertas vanguardias de los años veinte y treinta. Los juegos verbales y la intención por romper a toda costa con los cánones del relato clásico se imponen como principios estructurales predominantes por lo menos dentro de la que se propone como "nueva narrativa". De ese modo, el llamado experimentalismo se convierte en una modalidad de factura del texto que busca explorar mucho más la conformación del discurso que la relación de historias. A ello se suma la puesta en práctica de actitudes intimistas que persiguen desentrañar el mundo interior de quien funge como sujeto básico de la narración: la nueva narrativa venezolana breve sufre así momentos de verdadera exacerbación y culto por la noción artística de lenguaje, término que se convierte en el caballo de batalla más discutido en los talleres literarios.

A todo lo dicho se suma el hecho de que la valoración de un texto literario se vuelve excesivamente dependiente de su supuesto nivel de abstracción y de su diseño tipográfico: a mayor complejidad en lo expresado, a mayor nivel de experimentación discursiva, mayores posibilidades de lograr un mejor nivel de valoración estética en el medio (sobre todo, por

\footnotetext{
${ }^{4}$ A modo de ejemplo, citemos apenas algunos títulos que hablan por sí solos y que pueden ser ubicados en la tendencia de la que venimos hablando: Andamiaje (José Gregorio Bello Porras, 1977), Metales (Emilio Briceño Ramos, 1980), Cuerpo Plural (volumen colectivo, 1978), Si muero en la carretera no me pongan flores (César Chirinos, 1981), Desde los otros lugares (Alberto Guaura, 1978), La sombra de otros sueños (Gustavo Guerrero, 1981), A través de una mirada (Sael Ibáñez, 1978), Narración del doble (Gabriel Jiménez Emán, 1978), Los escribientes moriremos (Teódulo López Meléndez, 1978), Armar los cuerpos (Antonio López Ortega, 1982), Feeling (Antonieta Madrid, 1983), Pieles de leopardo (Humberto Mata, 1978), Aves de madera (Gustavo Morales Piñango, 1978), Ningún espacio para muerte próxima (José Napoleón Oropeza, 1976), Negro lógico (John Petrizzelli, 1978), El agresor cotidiano (Ednodio Quintero, 1978), etc.
} 
parte de la nueva crítica). El textualismo se convierte en la estética imperante. Es natural que con ello se modifique también la noción de lector modelo, a quien se le impone a cualquier precio una postura casi detectivesca cuyo solaz primordial radique en el regocijo de la palabra y sus significados (generalmente dispersos), en el juego de la armazón de rompecabezas lingüísticos habitualmente diseñados en forma fragmentaria en los abismos existenciales del narrador, y que acepte el juego sin intentar explicaciones que vayan más allá del placer por la palabra.

Un poco como puntos culminantes de este proceso ocurren dos acontecimientos que pudieran considerarse como el vértice de esta "nueva estética" que venía a desplazar las aspiraciones comprometidas de los escritores de la década anterior. El primero de ellos tiene que ver con la concesión bastante polémica del premio del importante Concurso de Cuentos de El Nacional al texto "Edictos, invictos, convictos", de Lourdes Sifontes Grecco (1981), autora novel proveniente del taller literario "Calicanto", coordinado por Antonia Palacios, galardonada en este caso por un jurado del que formaban parte dos escritores cuyas inclinaciones estéticas hacia el textualismo ya eran evidentes: Antonieta Madrid y Oswaldo Trejo (el tercero era Héctor Malavé Mata, a quien se pudiera incluir dentro de una estética narrativa menos experimental, pero no demasiado lejana de la de los otros dos autores). El otro hecho relevante será el que sirva de punto de partida para el resto de este análisis. Se trata de la publicación en libro del conjunto de textos titulado Al trajo trejo ... (1980), en el que Oswaldo Trejo recogía su producción de narrativa breve más importante producida precisamente durante ese lapso que Luis Britto García había denominado la "década miserable" (los años setenta). Justamente el decenio durante el que se alimenta dentro de la narrativa un espacio más que propicio para que la crítica posterior hable de la instauración de unos textos literarios que jugaban a la actitud siempre riesgosa del "relato imposible" (véase Jaffé 1991), esto es al cultivo del texto narrativo que busca (metaficcionalmente o no) negarse a sí mismo a través de la dispersión y confusión de la anécdota y que muestra apenas el diseño de un discurso mediante el cual el escritor persigue comunicarse consigo mismo más que con algún destinatario concreto.

Amparada entonces en el revivir de técnicas retomadas de la vanguardia, de los recursos de la llamada poesía experimental, de ciertos preceptos del surrealismo la nueva narrativa afianza en el país una postura declaradamente elitesca y se solaza en la producción de un conjunto de textos que se muestra casi inaccesible para el común de los lectores.

Hemos tratado de buscar una referencía contextual que permita entender el rumbo definitivo asumido por Oswaldo Trejo, dentro de una línea de trabajo en la que - por lo menos en lo que respecta al cuento- ya no habrá dudas sobre su postura muy personal, y ahora sí radical, ante la concepción del texto narrativo como objeto verbal cuyo destino final propone la anulación tajante del destinatario o al menos su reducción al mínimo. Una postura que se focaliza en el objetivo muy concreto de dejar a un lado casi todos los elementos que la teoría literaria y la lingüística del discurso han destacado como tipificadores de la textualidad implícita en una narración: nociones como las de "narrador", "personaje", "acción", "temporalidad", "secuencialidad", "coherencia narrativa", etc. son obviadas a la hora de proponer un discurso que pareciera negar de entrada el acceso a un lector concreto con lo que la posibilidad misma del escritor desaparece como tal y, por ende, la literatura finaliza consumiendo sus propias condiciones de existencia. Una posición riesgosa, pero 
no menos interesante por cuanto la negación total de sí mismo tiende a convertir al texto literario en un recurso metaficcional que puede resultar paradójico: se produce el texto mediante mecanismos similares a aquellos de que se ha valido la tradición literaria y se lo propone como tal. Se vale de los mismos recursos materiales y promocionales para ponerlo a la disposición de los lectores (publicación, colocación en el mercado, promoción, etc.). Sin embargo, la violación premeditada y radical de algunas normas canónicas de la creación literaria como fenómeno de comunicación impide que el discurso llegue a un buen número de los lectores concretos. Se trunca entonces la circularidad de un mecanismo en el que el discurso producido por el emisor pasa a ser apreciado como "burla", como "juego", o como cualquiera otra cosa, aunque en ningún momento se lo deje de considerar como "literario".

La consagración del escritor como participante de una categoría social y funcional a la que la sociedad le ha asignado un rol determinado, puede dar origen a que en el contexto se considere como literario todo lo que el mismo propone como tal. En ese sentido es posible hipotetizar que ningún lector concreto de la década de los setenta u ochenta se atrevería a negar la "literaturidad" de un volumen como Al trajo trejo troja trujo treja traje trejo (1980), por muy extraño o curioso que el mismo pueda parecer. Siendo sinceros, se trata de un volumen muy poco leído realmente por el común de los lectores (es decir de aquellos escasos lectores que habitualmente se acercan voluntariamente a un libro venezolano de narrativa). Pero por otro lado, opera el funcionamiento de la recepción que ofrece la crítica acerca de ese libro, ámbito dentro del cual se puede apreciar que fue bien recibido. Un ejemplo concreto de ello lo constituyen las diversas reseñas laudatorias de que fue objeto sobre todo de parte de escritores de las más nuevas promociones (Ej.: Santaella 1982; Romero 1981; Rivasáez 1980; Olalquiaga 1982; Mannarino 1980; Crespo 1980; etc.). Y esto sin olvidar la recepción muy alentadora que parte de esa misma crítica emergente le había otorgado a sus dos novelas anteriores (Andén lejano y Textos de un texto ...).

Sin duda que los textos de Al trajo trejo ... y Una sola rosa ... poseen peculiaridades que son reflejo de la trayectoria del autor y que no se trata de que por sí mismos sean absolutamente vacíos de significado. El problema es que parecieran intentar volver tan independiente la palabra del contexto que finalizan provocando esa impresión en el lector común. Pero contribuyen también en la consolidación de posturas estéticas ya implícitas en los libros anteriores. Se ratifican, por ejemplo, algunos recursos propios de la metaficción o escritura narcisista a los que el autor había realizado ya algunos acercamientos en sus libros precedentes. Se explicita el fenómeno de categorización de los escritores en tradicionales y no tradicionales, cuestión que también había sido planteada en un cuento anterior ("Horas escondido en las palabras", 1963) y que retoma ahora en "Memorandum para cuando vuelva Dante".

En Al trajo trejo ... nos encontraremos con una selección de textos que el editor presenta en la contraportada como narraciones "oblicuas" y "elusivas" en las que "la anécdota, totalmente secundaria, se plantea como un misterio". "La inclinación épica de algunos de los relatos de libros anteriores desaparece casi totalmente; la "historia", el hilo narrativo de la mayoría de los textos allí incluidos se vuelve tan difusa y tan inaprehensible que a veces luce como inexistente. Hecho que en ocasiones pone al lector en la dificultad 
de poder articularlos macroproposicionalmente, rompiéndose de esa manera cualquier posibilidad de comunicación que no sea la de leer por leer (deletrear), esto es, sin esperar la consecución de algún significado o sentido específico. El establecimiento del pacto de lectura se hace dificultoso por cuanto el lector convencional queda desamparado ante la presencia de unos textos que supuestamente son "narraciones" y que no le ofrecen ninguna oportunidad de aprehensión a menos que se apreste a entrar en el juego de la exégesis y se disponga entonces a decodificar mediante procedimientos analíticos lo que parece indecodificable a simple vista.

Valiéndose de la noción de lector implícito y/o lector ideal, alguien puede argumentar que no se trata de una total actitud de indiferencia ante el lector potencial sino de un incremento en los niveles de exigencia pautados por el texto. Sin embargo, en ocasiones el relato se vuelve tan intrincado, $\tan$ sin sentido, tan apegado al juego lingüístico, que termina proponiendo la concepción de un lector ideal casi inexistente (véase "Memorandum para cuando vuelva Dante", "Con el marrano atrás" y "Cuando nosotros cuando" y la mayoría de los textos de Una sola rosa ...). Aquí el discurso trejiano propone un rumbo tan particular para el cuento, que finaliza lindando los terrenos más radicales de la "antinarrativa". La situación es tan importante que como pudo haberse pensado para algunos cuentos anteriores ya ni siquiera puede decirse que los destinatarios ideales sean los mismos escritores. La admiración que se pueda sentir hacia ese tipo de textualidad, el presunto acercamiento entusiasta de la crítica más joven, no dejaría de ser una contemplación ciega de parte de quienes ven en esos libros en particular, y en Trejo, en general, un representante del modelo de escritor engendrado en el contexto histórico-social del que hemos hablado arriba. La alabanza no es más que un reflejo del juicio y la valoración con que la crítica oficial ha consagrado la ubicación de Trejo como autor de textos literarios. De modo que hasta puede pensarse que no se está juzgando solamente la pertinencia específica del libro, sino también su funcionamiento dentro de un sistema más amplio, que incluye toda la obra última, con la que Trejo ha venido extremando sus rechazos hacia el discurso narrativo canónico, sin olvidar que también su propuesta puede finalizar convirtiéndose en un canon. Violando todas las normas, el autor se hace importante. La extrañeza será precisamente su rasgo diferenciador, propuesta que como bien sabemos ha prosperado también en otros países de América Latina, pero que constituye en Venezuela un caso bien particular, al tocar el extremo más lejano de un espectro en cuyo punto más opuesto estarían quienes rinden culto a la anécdota transparente y a los rasgos normativos de la narración ortodoxa.

Vayamos a algunos detalles que permitan ejemplificar la situación descrita.

El primer texto con que nos topamos en Al trajo trejo ... es "Hermana, ¿cómo conseguirlos?", superficialmente caracterizado por una materia discursiva altamente descriptiva, aunque es innegable que con cierto esfuerzo el lector pudiera inferir la subyacencia de una historia, reconstruible tal vez en macroproposiciones pero en un nivel muy global. Es decir, las supuestas secuencias de esa historia no están realmente explicitadas en el nivel del discurso, sino sugeridas a través de ciertos indicios o claves, incorporados como parte del marco (descripción del ambiente y referencia muy fugaz los personajes) o como interrogantes de la voz textual que presenta los hechos: 
La casa está como para recibirlos a todos, despojada de basuras, sólo con unas boronas en la mesa.

Entre la madre como era y el joven amante como es.

Porque es de condenar este amor entre la madre y el amante (Trejo, Al trajo 10).

¿Y dónde están? ¿A dónde fueron?

El cuarto está vacío y bien acomodadito, como en día de domingo cuando la madre era pensada y le tenía tanta lástima por ese enamoramiemto suyo ...

No poder defender a la madre si es atacada por el amante. Porque a fin de cuentas forman despareja y el amante habrá de concluir por pegarle y humillarla (Trejo, Al trajo 11).

Sin que se pueda precisar en ningún momento la evidencia de un narrador que dé cuenta de la historia, el lector intuye la espera angustiosa de unos hijos ante la partida de la madre con un amante joven y cuyo paradero se desconoce. Esta situación es apenas inferible como información implícita del texto, cuyo diseño verbal se sostiene básicamente en la descripción del marco espacial y gramaticalmente marcado por el predominio de tiempos verbales en presente y formas verbales no conjugadas (véase Weinrich 1974). Aparte de la voz textual que se encarga de delimitar el escenario o marco y de plantear desde el título una serie de interrogantes sobre lo que pudiera constituir la historia, un neutral y lejano sujeto de la enunciación, se hace notoria la ausencia del tono narrativo directo $\mathrm{y}$, en consecuencia, de un narrador localizable mediante marcas textuales específicas. El texto es presentado como si estuviéramos apreciando la distribución de los elementos de una obra pictórica (¿una estampa?) y dedujéramos a partir de allí la posibilidad de una historia. Un texto que pudiera muy bien entrar en la caracterización del "cuento estático" de la que habla Friedman (véase Pacheco y Barrera 1993). Similar al de algunos de los cuentos de Los cuatro pies, este rasgo pareciera tipificar buena parte de la producción que Trejo recoge tanto en Al trajo trejo ... como en Una sola rosa ... y tiene mucho que ver con el acercamiento que algunos críticos observan entre su narrativa y el discurso lírico (véase por ejemplo, Pérez Huggins 1983; Tedesco 1981; Jaffé 1991).

Una apreciación similar pudiera hacerse para el texto titulado "Demasiada coincidencia", bastante parecido al anterior en cuanto a la creación de cierta atmósfera en la que subsisten el distanciamiento del sujeto de la enunciación y la frecuencia de la materia descriptiva. Aunque puede decirse que ahora se muestra un poco más cierto movimiento de personajes y la posibilidad de inferir mejor algunas secuencias en las que éstos participan, gracias a un mayor número de claves superficiales evidenciadas ya desde el párrafo inicial:

No fueron llamadas a casa.

La casa ihasta con una capilla!, sin la sagrada familia que se ocupe de ella.

Comadre ni ahijada fueron llamadas, invitadas. ¡Llegaron al hogar! ¡Dirían alguna cosa improcedente, porque! ... Tal vez pidieron café y nada más. Acaso, exigieron a la sagrada familia que aseara la cocina. Porque, de un todo, la sagrada familia dejó la casa y en otra debe estar sirviende. Quizás tenía motivos para hacerlo, ajenos al de la llegada de la madrina y ahijada, coyuntura esperada quién sabe desde cuándo. (subrayados míos, Trejo, Al trajo 15).

El problema para la percepción del lector y para la continuidad del tono narrativo radica en que, aparte de lo expresado en ese párrafo introductorio, en el resto del texto 
ocurren muy pocas cosas más. Casi todo reitera de alguna manera lo sintetizado en esas primeras líneas, de manera que lo que parecía ser el comienzo de un relato más extenso termina convirtiéndose en un mecanismo circular que da vueltas sobre lo mismo: la partida de "la sagrada familia", el personal de servicio de la casa y las consecuencias de ello. El escaso tono épico inicial se diluye entonces a medida que el texto avanza, dejando en el lector una sensación de estatismo. Es obvio que en estos casos el autor se preocupa muy poco por dar alguna relevancia a la "historia", hecho éste que igualmente será tipificador del contenido de Una sola rosa ... y que no va a ser demasiado diferente en buena parte del contenido de Al trajo trejo..., sobre el que habría muy poco que agregar al respecto ("Ellos llegaron con sombrero de copa", "Antes de la misa en Re", "Entre dama y caballero", "La provocación", "El ábol de las dos mitades, "La exaltación", etc.). Elementos como la "intensidad", el "efecto sorpresa", el "suspenso", la concatenación de episodios que concluyen en el diseño de una trama, tan familiares dentro del modelo de cuento épico o de la narración canónica (van Dijk 1983), no se vislumbran aquí por ninguna parte. El cuento se concentra esta vez en la descripción del marco, como si se despreciara el suceso. De allí su cercanía con la prosa lírica. Cuando la teoría del texto narrativo ha atribuido a éste su especificidad a partir de rasgos como el movimiento y la sucesión temporal, buena parte de la producción de $A 1$ trajo trejo ... y de Una sola rosa ... se empeña en resaltar precisamente la ausencia de ellos, razón por la cual pudiera dudarse también de su condición de "libros de cuentos", en el sentido más tradicional. "Ahí, en vez de en el lugar" es por ejemplo un texto modélico en el sentido de destacar la carencia de movimiento. La voz textual parte de una estructura adverbial para referirse a alguien detenido bajo el marco de una puerta. Se juega a una especie de descripción en vaivén que se aleja o se acerca al mismo objetivo:

Donde no había estado estaba, ahí, sorpresivamente ante el marco de la puerta. De extrañar tanto más ahí, en el umbral, que en el lugar mismo con altas, anchas puertas, innecesarias por estar siempre abiertas.

Los marcos de las puertas, visibles desde ahí hasta el final, acaso conduzcan al único lugar de las esporádicas llegadas donde la espera siempre juega a eso de llegará, no llegará, posiblemente llegue (Trejo, Al trajo ${ }^{* * *}$ )

En otras oportunidades, llega incluso al diseño discursivo que va mucho más allá de estas posibilidades: así, "Ahí, en vez de en el lugar", "Pensando el miedo" y "Cuando nosotros cuando" parecieran avanzar en el afán de perseguir muy poca sintonía con el receptor al añadir a todo lo anterior (estatismo, ausencia de personajes, lirismo, carencia de desarrollo temporal) la violentación de las normas semánticas y sintácticas del idioma:

Sumando el tiempo de las esperas siempre largo en el lugar de las no llegadas, donde solamente aparece de vez en cuando, tanto más inesperado resulta que haya estado ahí, en el umbral. ¡Ahí estuvo! ¡Ha estado ahí, ante el marco de la puerta ("Ahí, en vez de en el lugar" 87).

Pensando el miedo, mayor es el miedo a los años del Prelado, avanzados avanzando y metiéndose en los unos años de quien el Prelado tenía pensando el miedo ("Pensando el miedo" 97). 
10, en vez de la frase cuándo, nosotros cuándo, con sus equivalencias: 10 por una vez, dos veces la frase, 10 por dos veces, tres veces la frase, 10 por tres veces, cuatro veces la frase, menos o más veces hasta el coito, y siempre de nuevo 10 , número para las solicitaciones de la Sota de Oros, más práctico que el nombre Sota de Bastos o que la frase suya cuándo, nosotros cuándo, cuándo el acoso mutuo hasta la posesión. ("Cuándo, nosotros cuándo" 125 ).

Adicionalmente, los textos muestran la peculiaridad de contener muy pocos conectores formales explícitos. Han sido díseñados, más bien, como series de imágenes superpuestas cuyo único vínculo es el tópico general tratado por el emisor, con la incursión circunstancial de ciertos momentos en que el tono discursivo pasa de lo predominantemente descriptivo al tono expositivo-argumentativo, sin aparente justificación:

Cheverísimo que el edificio no tuviera puertas ni ventanas. ¡Un calificado funcionario utiliza esa palabra! Fue aceptada y ya viene en alguna correspondencia. En vez del tengo a honra avisar recibo de su atenta nota, escriben chévere nota. Tampoco se dice avisar recibo sino avisar el recibo de su atenta nota. También, de paso, ustedes usan mucho eso de a celebrarse, en lugar de que se celebrará, porque como le tienen tanto miedo al que por no saber usarlo, caen en peores errores al rehuirlo ("Ellos llegaron con sombrero de copa" 23).

Analizados localmente, algunos de los "relatos" lucen incoherentes y es preciso recurrir al nivel global para encontrar algún posible significado de los mismos. Es obvio entonces que el lector concreto es aquí prácticamente forzado a plantearse la lectura más como un ejercicio de decodificación voluntaria que como actividad recreativa, generadora de placer (a menos que ese mismo mecanismo decodificatorio despertara algún placer particular en ciertos receptores). Y si éste no estuviera dispuesto a asumir su rol de analista forzado, se desnaturalizaría entonces la función comunicativa propia de todo texto literario, truncándose de ese modo cualquier posibilidad de pacto de lectura. Más adelante podremos observar cómo este procedimiento alcanza niveles de radicalización en un texto como "Con el marrano atrás".

Quisiéramos ahora detenernos ahora en la parte del libro que a nuestro criterio resume su propósito general, la que se titula "Memorandum para cuando vuelva Dante". El conjunto estructural de la misma propone una demarcación formal bastante específica. Plantea la espera de la llegada de Dante, a quien un narrador, que aquí sí se hace explícito, alude constantemente, apelándolo como si dudara de su identidad (Dante: "como te llames", "como vayan a llamarte", "como quieras llamarte"). En consonancia con su referente literario más notorio, propone una división de estratos parecidos a aquellos de la Divina Comedia: Dos hileras de escalones numerados: una correspondiente a los números pares (del 10 al 2), otra a los impares (del 9 al 1). Sin referencialidad espacial ninguna, cada escalón corresponde a la ubicación de cierta tipología de personajes muy particulares. El narrador se vuelca de nuevo abiertamente hacia la actitud autorreferencial a lo largo del “Memorandum ...", se intuye la posibilidad de diferenciación de dos tipos de literatura: uno, predecible, anecdótico, quizás localista, limitado al contexto socio-histórico inmediato: el otro, cercano a lo inesperado, ajeno tal vez a lo local, casi siempre descontextualizado 
histórico-geográficamente de lo inmediato, $\mathrm{y}$, al parecer, relacionado con la proposición general en que entraría la obra de Dante.

En el cuento se plantean las aspiraciones de renovación de los más jóvenes -de los renovadores - desconocedores de pautas y optimistas para el cambio, quienes incialmente tienen como destinatario y como modelo a Dante. Pero se sugiere también el cambio de postura que pudiera ocurrir al sumarse éstos a los "agrupados, asociados, organizados" en el escalón diez. Digamos que ello explicaría parcialmente la actitud y la escritura de quien en buena parte de su producción literaria última ha intentado ser distinto, permanecer al margen de los "asociados" y participar del sistema literario venezolano muy desde la periferia de lo establecido. Hay aquí una cierta intención paródica que se ratifica cuando vemos que el escalón número ocho es el lugar para lo folclórico, el espacio para los "telúricos", quienes "se apretujaban para darle paso a sofisticados pájaros guarandoles, pájaros sebucanes, indios con la culebra a cuestas ..." y a los que debería encargarse la "presentación del espectáculo del día del recibimiento" (Trejo, Al trajo 52).

Por otro lado, melenas, minifaldas y blue jeans se ubican en el escalón número nueve, aspiran constantemente a la ruptura, pero también ansían el ascenso hacia la parte interior del escalón superior:

Los tiros al blanco de melenudos y minifaldas eran sus tumultuosos señalamientos y señales dilapidatorias de costumbres, y conducianse en el escalón, noblemente, generosamente, de manera distinta de como ... se comportaban ... enseriados, por más edad, o por resabios, ... llevando pelo corto y corbata ... y aún más sometimientos, acaso ya aspiraban ... a competir con los agrupados, asociados, organizados (Trejo, Al trajo 48).

Este "Memorandum ..." vendría a ser el cuento donde el autor pone a disposición del lector algunas de las claves que le permitirán decodificar el resto de los textos contenidos en el libro, así como también los incluidos en Una sola rosa... Si dejamos a un lado cierta estructuración sintáctica, en ocasiones altamente compleja y las constantes violaciones gramaticales registradas tanto en los subtítulos como en el resto del cuento (P.e.: "En inesperado estado, unos, lo nunca habías atestado de urgidos, viendo escalones", (Trejo, Al trajo 47)) puede decirse que el recurso textual más importante del mismo radica en la inclusión de una serie de tachaduras incorporadas como parte del texto definitivo y operan como claves que explicitan abiertamente para el lector el proceso de confección del mismo. Sin lugar a dudas, que este detalle no deja de ser innovador si nos quedamos únicamente en su utilización como recurso tipográfico. No obstante, puede contribuir también a convertirse en elemento perturbador para la percepción del lector concreto, quien en todo momento es instado a enfrentar aquello como un "borrador" en el que permanecen incluso las tachaduras, que a su vez operan como factor distractor de la coherencia del discurso. Incluso, llega un momento en que el narrador alude autorreferencialmente a ello:

Para tales novatos otras eran las exigencias, superar escollos, grandes dificultades dirían ellos, de tocarles escribir este borrador de un Memorandum, ya con tantas tachaduras (Trejo, Al trajo 49). 
Independientemente de su tendencia, en el cuento todos los escritores aparecen relacionados con el escalón número diez, pero no en la misma dimensión. Los primeros lo disfrutan desde adentro: se les llama los "acometedores". Los segundos estarían fuera del escalón sin poder entrar.

Más adelante, la narración muestra explícitamente una concepción de lo literario que se corresponde en buena parte con aquella bajo la cual ha sido elaborado el libro en su totalidad:

Tan atado estan el Conde [Ugolino] a tradiciones que, lamentablemente, tampoco lo ntraban por la boca, ni aun empujándolos para una digestion estomacalen vez do intelas ciertas obras literarias tampoco le merecían el mínimo esfuerzo de ir más allá de los primeros párrafos o versos, bloqueados como tenía los mecanismos de conocimiento para asimilar muchas de las obras válidas a su alcance, ermaneciendo quién sabe en qué otro escalón permele de las artes ¡y mucho menos me complacen, mi hermanazo!, las explicaciones que recibo más confusas que las obras (Trejo, Al trajo 63).

Hay aquí una directa y paródica alusión a cierto tipo de crítica cuya comprensión suele hacerse más difícil que la de los textos que analiza. Y también la reiteración de una dicotomía que diferencia la literatura de acuerdo con el "modelo" estético al que se adhiera. Curiosamente, el planteamiento reproduce autorreferencialemente lo que muchos otros escritores pudieran opinar de la narrativa experimental trejiana: ¿Trejo parodia a Trejo? No sería nada extraño que así ocurriera por cuanto hemos venido observando en la evolución de su obra un permanente arraigo hacia cierta actitud sarcástica que (muy en el estilo de Jorge Luis Borges) pone en tela de juicio su propia producción, aunque en boca de un personaje distinto del narrador, lo que a su vez implicaría una respuesta ante quienes han decidido "unánimemente permanecer a espaldas del espejo": los "telúricos" (Trejo, $A l$ trajo 61): ¿Encuentro involuntario con los postulados de eso que se denomina postmodernidad?, ¿Disolución del macrodiscurso que históricamente ha caracterizado lo narrativo?

La propuesta implícita en esta escritura se postula entonces como una búsqueda para que la literatura se despeje de un anecdotismo repetitivo y siente su base fundamental en el soporte de la palabra. Esto puede parecer o no original, sobre todo si recordamos movimientos como el concretismo brasileño y celebridades ligadas a la llamada "poesía experimental" (Mallarmé, Apollinaire, Pound, etc.), pero pareciera por lo menos bastante arriesgado en el ámbito de una narrativa como la venezolana, invadida casi durante todo el siglo por una avalancha anecdotista y marcada por el peso de una escritura que no se propone como eje de su propio desarrollo, sino que más bien descansa en pocas innovaciones de carácter formal, salvo escasas excepciones como las de Julio Garmendia, Antonio Márquez Salas, Enrique Bernardo Núñez, Guillermo Meneses y Arturo Uslar Pietri, para recordar sólo algunos casos suficientemente representativos dentro de la narrativa.

El problema con la situación particular de este autor -y de todos aquellos que de alguna manera militan en su misma estética- es que su propuesta puede conducir a la aniquilación misma del texto narrativo como tal. Quizás el riesgo sea mucho menor en el terreno de la poesía, donde lo "experimental" ha sido bastante probado y comprobado 
como recurso de innovación estética, generalmente aceptado por los aficionados a esa modalidad. El ludismo verbal puede resultar interesante si se le dosifica de acuerdo con las posibilidades de la competencia narrativa del receptor de nuestro tiempo: las marcas textuales y contextuales del discurso narrativo soportan efectivamente cierto regodeo y alguna manipulación lúdica, pero siempre que no se rompa con determinados esquemas cognoscitivos establecidos para el procesamiento mental de esa tipología discursiva. Nuestra creencia es que esa posibilidad continúa vigente en algunos de los textos de Al trajo trejo ..., ("Safo", "Memorandum ...") pero se ve seriamente amenazada con el penúltimo y último de los relatos allí incluidos, "Con el marrano atrás" y "Cuándo, nosotros cuándo", construidos ambos con excesivo apego a la distribución espacial de los grafemas y a los juegos tipográficos y fraseológicos, con una absoluta indiferencia hacia la estructuración de los contenidos. Esta tendencia ya se percibía en obras narrativas anteriores de Trejo (Andén lejano, 1968; Textos de un texto con Teresas, 1975) y se consagrará con la aparición de su último libro de cuentos conocido (Una sola rosa y una mandarina, 1985) y su más reciente novela (Metástasis del verbo, 1990).

"Con el marrano atras" es, por ejemplo, un texto en el que el juego tipográfico es llevado a su máxima expresión. Aparece construido en dos sub-textos paralelos: uno amplio, en la parte central de la página y otro en su margen izquierdo. Veamos sólo el comienzo:

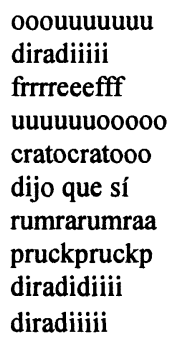

Nonollisa, los hijos de viejos nacen arrugaditos y canosos. Por eso sois así, y todos los que están con uno semejante, hablando de remotos hechos o de cosas recien ocurridas. Como todos, con una vida precariamente corta, fijada para que apenas estén en un solo sitio, sin invadir otros, sin hacer los largos recorridos. Vida para que estén y sean en un tiempo mínimo (Trejo, Al trajo 109).

Pudiéramos reproducir aquí el texto total sin mucha posibilidad de que ello pueda aclararle al lector los propósitos del mismo. En ocasiones ambos discursos se entrecruzan y el de la derecha se convierte entonces en la continuidad de lo que algunos críticos denominan la "banda sonora" colocada a la izquierda. Los recursos tipográficos y espaciales aquí destacados se complementan con alteraciones permanentes de la sintaxis, hecho que origina en el lector una especie de caos que prácticamente lo obliga a abandonar el texto. Si en algunos casos, hemos apreciado la obra de Trejo como meritoria dentro de la narrativa venezolana en algunos aspectos formales, en casos como éste se hace difícil sostener esta afirmación. Ya no se trata de la fabulación fantástica. Tampoco de la oposición realidad física/realidad otra, ni de atractivas propuestas metaficcionales. Lo que se puede apreciar en textos como éste es sencillamente el abandono de la palabra a su libre albedrío, actitud que vuelve a la literatura un objeto inútil para cualquier finalidad. En una exacerbación de ludismo altamente peligrosa para el lector contemporáneo, el texto transmite el mismo caos que le sirve de marco referencial (una capital congestionada de ruidos y de tránsito 
automotor, la evocación de un pasado remoto a través del Marqués Casa de León, frases publicitarias reiterativas, expresiones dialectales, expresiones en lengua inglesa). Si ese fuera su propósito, entonces es obvio que lo logra. Pero en el momento de buscar alguna coherencia y cohesión textuales que permitan organizar los contenidos del mismo en la memoria semántica, el propósito se vuelve inútil. No parece haber modo probable de que este texto en particular logre despertar algún interés que no vaya más allá de la simple curiosidad por lo extraño de su diseño. En fin, un texto caótico como sus propias proposiciones temáticas y su organización estructural. Una escritura cuyo soporte casi se queda en el nivel de los significantes, incapaz de conmover a quien no fuere su mismo autor. Una escritura que rechaza intencionalmente su destino comunicacional, el encuentro posible con un receptor que no esté dispuesto a entrar en el juego de indagación de la intertextualidad que la misma implica. Un documento literario que está anunciando el camino de un diseño tal vez mucho más arriesgado que éste: aquel que ya asomará en el último de los textos de Al trajo trejo ... ("Cuándo, nosotros cuándo"), y que se reiterará en algunos de los breves ejercicios de Una sola rosa ... ("Una sola rosa y una mandarina", "El comprador vendido", "Siempre separadas", "Otra transparencia", etc.) y que será el caballito de batalla primordial del último libro que el autor ha publicado hasta el presente: Metástasis del verbo. Se trata de la elisión superficial definitiva del verbo en forma conjugada. Esto es, de una categoría gramatical tan importante para la coherencia de la narratividad en el nivel de la estructura superficial. Pretendiendo eliminar el verbo de la estructura superficial, Trejo se arriesga definitivamente a aniquilar la aprehensión que el lector pueda hacer de relaciones de temporalidad en el texto y, en consecuencia, las acciones que puedan ocurrir sólo serían inferibles a partir de cierto procesamiento mental que a su vez convierte la lectura en una conducta autorreflexiva. Es natural entonces que en tiempos como los nuestros, en que la anécdota ha vuelto a ser tan importante para la narración, el lector se niegue a ingresar en los juegos verbales que este singular escritor le plantea. Si algún logro posible pueda haber en esto, parece ser la demostración de que comunicarse a través de un hecho de lenguaje como la literatura no es una verdad de perogrullo como suele suponerse. Dos fragmentos extraidos de Una sola rosa ... sirven para ilustrar tal afirmación:
Al cuerpo vendido el adonde iba el cuerpo, a ese, a ese mismo comprado el adonde va. Adonde yendo el cuerpo, por algún tiempo, usable todavía: a otro cuerpo innecesario y distinto del también vendido, lugar ahora, lugar a oscuras, cuerpo, antaño, bajo la luz más plena, ... ("El comprador vendido" $\mathrm{s} / \mathrm{p}$ ).
En donde de cada ser dos, de cada cosa de exactas, una para sí y otra para alguien. Siendo así, de algunas, una a la memoria y otra dejable en el lugar, ya el barrio en el caserío o el caserío en el barrio, ya los árboles frutales, las puertas, el automóvil, entrado en contravía y el automóvil llegado por el otro lado, ambos con movimiento y ruido de carro ("Una sola rosa y una mandarina" s/p).

No se trata de "comprender" o no ciertos contenidos; por lo general algún contenido es evidente en esta clase de textos. De hecho, la simple presencia de una palabra remite necesariamente a algún referente. Pero en estos casos lo que parece faltar es la necesaria cohesión que dé al texto total alguna forma semántica determinada. Se percibe el juego del autor, se evidencia su interés por violentar normas estéticas y gramaticales, pero sin 
proporcionar una posibilidad de apertura hacia el universo experiencial del receptor. Se traspasan los límites de lo comunicable y el texto se revierte entonces sobre sí mismo. Vale para sí y quizás para su autor, pero no para los demás. Ese solo hecho sería suficiente para explicar su bajo nivel de recepción en el panorama de la narrativa venezolana actual. La longitud, los propósitos, el contexto psicológico, y el marco contextual general, requeridos por las particularidades del texto narrativo, exigen la permanencia de unos requisitos mínimos que, sin negar las posibilidades de la innovación, mantengan al receptor integrado al hecho comunicativo que es la literatura. La violación de este requisito lesiona de alguna manera las posibilidades de concreción de cualquier proyecto literario. Esto es improcedente con la literatura por cuanto ya sabemos que la misma es producida para funcionar en lo que van Dijk denomina un "contexto comunicativo público". Pero tiene, por otro lado, los méritos de agredir sin reparos el clima de una tradición literaria que, por más que acepte abiertamente los principios de la estética por la estética, coloca también unos límites hasta donde es posible llegar. Todo texto que intente deslizarse más allá de esa frontera encontrará natural resistencia entre los lectores potenciales de literatura. Eso es precisamente lo que hace Oswaldo Trejo con sus obras más radicales y eso precisamente- lo convierte en un caso estudiable en la literatura venezolana.

\section{BIBLIOGRAFÍA BÁSICA Y REFERENCIAS}

Antillano, Laura. "Oswaldo Trejo al encuento de la palabra". Revista Nacional de Cultura, 205. (Caracas, 1972): 21-37.

Bajtín, M. Estética de la creación verbal. México: Siglo XXI, 1983.

Bal, Mieke. Teoría de la narrativa. Madrid: Cátedra, 1987.

Barrera Linares, Luis. Memoria y cuento, treinta años de narrativa venezolana. Caracas: Contexto Audiovisual 3/Pomaire, 1992.

Crespo, Luis Alberto. "Con T de Trejo". Papel Literario (Caracas, 27 abril 1980): 4.

Dubois, Jacques. "Lectura y condiciones de legibilidad". Criterios, 5-12. La Habana: Casa de las Américas, 1984.

González, Beatriz. "Sistema narrativo e imaginario social de la Venezuela Petrolera (décadas '70-'80)". Ponencia. Coloquio: "Latin America: New Directions in Literary Theory and Criticism". Hanover, NH: Dartmouth College, 1988.

Halliday, M. "Función lingüística y estilo literario". Exploraciones sobre las funciones del lenguaje. Barcelona: Médica y Técnica, 1982a.

El lenguaje como semiótica social. México: Siglo XXI, $1982 \mathrm{~b}$.

Hunter Brown, S. "Discourse Analysis and the Short Story". S. Lohafer y J. Clarey, Short Story at the Crossroads (1989): 217-248.

Hutcheon, Linda. Narcissistic Narrative. The Metafictional Paradox. Nueva York: Methuen, 1989: 168.

Jaffé, Verónica. El relato imposible. Caracas: Monte Ávila, 1991.

Lasarte, Javier. "La cuentística de Oscar Guaramato". Sobre literatura venezolana.

Caracas: La Casa de Bello, 1992: 107-122.

Lyons, J. Lenguaje, significado y contexto. Buenos Aires: Paidós, 1983. 
Macht de Vera, Elvira. Indagaciones en el universo narrativo de Oswaldo Trejo. Caracas: Fundarte, 1982.

Mannarino, Carmen. "La palabra como juego serio". El Nacional, C-20 (Caracas, 26 abril 1980).

Olalquiaga, María Celeste. "El único lugar de la escritura". Papel Literario, diario El Nacional (Caracas, 24 octubre 1982).

Oropeza, José Napoleón. Para fijar un rostro. Valencia: Vadell Hermanos, 1984.

Ortega, Julio. "Oswaldo Trejo y la naturaleza exploratoria de una escritura". Imagen, 100-76. Caracas: CONAC, 1991.

Pacheco, Carlos y Luis Barrera Linares (comps.). Del cuento y sus alrededores. Aproximaciones para una teoría del cuento. Caracas: Monte Avila, 1993.

Pérez H., Argenis. "La narrativa neobarroca de Oswaldo Trejo". Ponencia IV SDILV. Publicada después en Imagen, 100-56. Caracas: CONAC, 1989.

Pratt, Mary Louise. Toward a Speech Act Theory of Literary Discourse. Bloomington: Indiana University Press, 1977.

Rivasáez, R. "Oswaldo Trejo al trajo". Página Literaria del Diario de los Andes (12 octubre 1980).

Romero, Denzil. “Al trajo, trejo, etc.”. El Nacional (Caracas, 23 diciembre 1981).

Santaella, Juan Carlos. "La invención de Oswaldo Trejo". Papel Literario, diario El Nacional (Caracas, 24 octubre 1982).

Tedesco, Ítalo. "La narrativa de Oswaldo Trejo". Ponencia: II Congreso de Escritores de Lengua Española. Caracas: La Casa de Bello, 1981.

Van Dijk, Teun. "Cognitive Processing of Literary Discourse". Poetics Today, 1 (1979). Estructuras y funciones del discurso literario. México: Siglo XXI, 1980. La Ciencia del Texto. Barcelona: Paidós, 1983.

Warning, Rainer (comp.). Estética de la recepción. Madrid: Visor, 1989.

Weinrich, Harald. Estructura y función de los tiempos en el lenguaje. Madrid: Gredos, 1974.

\section{Bibliografía directa de Oswaldo Trejo}

Los cuatro pies (cuentos). Prólogo de Claudio Vivas, viñeta e ilustraciones de Mateo Manaure. Caracas: Tipografia la Nación, 1948. Contiene siete cuentos: "Las garzas negras", "Escuchando al idiota", "Deambular fatal", "Sin anteojos al cuerpo", "Volver a nacer", "Nocturno sideral", "Los esqueletos que se encontraron".

Cuentos de la primera esquina (cuentos). Caracas: Ediciones Cruz del Sur, 1952. Contiene siete cuentos: "Ojos en la bóveda de Dios", "Un cuento de mar", "Rayas y paraguas", "Así es como son", "Climaterio", "Aspasia tenía nombre de corneta", "Las lunas de San Juan".

También los hombre son ciudades (novela). Caracas: Monte Ávila Editores, 1962.

Depósito de seres (cuentos). Col. de temas y autores merideños, 5. Mérida: Ejecutivo del Estado Mérida , 1965. Contiene siete cuentos: "El cuarto", "Victoria", "Una oferta de trabajo", "En verde, en oscuridad, en carnes", "Las islas", "Horas escondido en las palabras", "El gajo de la tarde". 
Andén lejano (novela). Caracas: Monte Ávila Editores, 1968.

Escuchando al idiota y otros cuentos (cuentos). Caracas: Monte Ávila Editores, 1969.

Contiene los cuentos incluidos en los tres primeros libros del autor: Los cuatro pies,

Cuentos de la primera esquina y Depósito de seres. Se excluyen los cuentos "Nocturno sideral", del primer libro, y "Ojos en la bóveda de Dios", del segundo.

Textos de un texto con Teresas (novela). Caracas: Monte Ávila Editores, 1975.

Al trajo, trejo, troja, trujo, treja, traje, trejo (cuentos). Caracas Monte Avila Editores, 1980. Contiene 15 cuentos: "Hermana, ¿cómo conseguirlos?", "Demasiada coincidencia", "Ellos llegaron con sombrero de copa", "Antes de la misa en Re", "¿Cómo te llamabas María?", "Safo", "Memorandum para cuando vuelva Dante", "La provocación", "Entre dama y caballero", "Ahí, en vez de en el lugar", "El árbol de las dos mitades", "Pensando el miedo", "La exaltación", "Con el marrano atrás", "Cuándo, nosotros cuándo".

Una sola rosa y una madrina. Mérida: La draga y el dragón, 1985.

Metástasis del verbo. Caracas: Fundarte, 1990.

Tres Textos Tres. Caracas: Monte Ávila Editores, 1992. Contiene las novelas Andén lejano, Textos de un Texto con Teresas y Metástasis del Verbo. 